\title{
A Direct Sulfation Process of a Marine Polysaccharide in Ionic Liquid
}

\author{
Nathalie Chopin, ${ }^{1,2}$ Corinne Sinquin, ${ }^{1}$ Jacqueline Ratiskol, ${ }^{1}$ Agata Zykwinska, \\ Pierre Weiss, ${ }^{3}$ Stéphane Cérantola, ${ }^{4}$ Jean Le Bideau, ${ }^{2}$ and Sylvia Colliec-Jouault ${ }^{1}$ \\ ${ }^{1}$ IFREMER, Institut Français de Recherche pour l'Exploitation de la Mer, Laboratoire Ecosystèmes Microbiens et \\ Molécules Marines pour les Biotechnologies, rue de l'île d'Yeu, BP 21105, 44311 Nantes Cedex 03, France \\ ${ }^{2}$ Institut des Matériaux Jean Rouxel (IMN), Université de Nantes, CNRS, 2 rue de la Houssinière, BP 32229, \\ 44322 Nantes Cedex 3, France \\ ${ }^{3}$ INSERM U791, Laboratoire d'Ingénierie Ostéo-Articulaire et Dentaire (LIOAD), Université de Nantes, 1 place Alexis Ricordeau, \\ BP 84215, 44042 Nantes Cedex 1, France \\ ${ }^{4}$ Laboratoire de Résonance Magnétique Nucléaire, Université de Bretagne Occidentale, CS 93837, 29238 Brest Cedex 3, France
}

Correspondence should be addressed to Agata Zykwinska; agata.zykwinska@ifremer.fr

Received 21 July 2014; Accepted 15 September 2014

Academic Editor: Paola Laurienzo

Copyright (C) 2015 Nathalie Chopin et al. This is an open access article distributed under the Creative Commons Attribution License, which permits unrestricted use, distribution, and reproduction in any medium, provided the original work is properly cited.

GY785 is an exopolysaccharide produced by a mesophilic bacterial strain Alteromonas infernus discovered in the deep-sea hydrothermal vents. GY785 highly sulfated derivative (GY785 DRS) was previously demonstrated to be a promising molecule driving the efficient mesenchymal stem cell chondrogenesis for cartilage repair. This glycosaminoglycan- (GAG-) like compound was modified in a classical solvent ( $N, N^{\prime}$-dimethylformamide). However, the use of classical solvents limits the polysaccharide solubility and causes the backbone degradation. In the present study, a one-step efficient sulfation process devoid of side effects (e.g., polysaccharide depolymerization and/or degradation) was developed to produce GAG-like derivatives. The sulfation of GY785 derivative (GY785 DR) was carried out using ionic liquid as a reaction medium. The successful sulfation of this anionic and highly branched heteropolysaccharide performed in ionic liquid would facilitate the production of new molecules of high specificity for biological targets such as tissue engineering or regenerative medicine.

\section{Introduction}

In cartilage tissue engineering, differentiation of mesenchymal stem cells into chondrocytes is crucial to obtain successful cartilage regeneration. The differentiation can be promoted by various biological agents, including polysaccharides. In peculiar, glycosaminoglycans (GAGs) were shown to participate in many biological processes including cell adhesion, migration, proliferation, and differentiation likely through interactions with proteins, such as growth factors, proteases, and chemokines $[1,2]$. The presence of sulfate and carboxylic groups in GAG structure determines the interaction through electrostatic interactions [1]. For instance, heparin, which is a GAG widely known for its anticoagulant and antithrombotic properties [3], has been employed in the design of materials as engineered scaffolds for tissue regeneration and controlled release platforms for growth factor delivery [4]. However, undesirable side effects of this sulfated polysaccharide, such as hemorrhagic complications, heparin-induced thrombocytopenia, and low bioavailability [5] as well as its mammalian origin increasing the risk of the presence of infectious agents (e.g., viruses and prions), considerably limit its biological applications. In this context, marine microorganisms, such as marine bacteria, producing exopolysaccharides (EPS) with unique structures, become a promising source of new GAGs-like molecules with a low risk of contamination by pathogenic agents. Indeed, a mesophilic bacterial strain discovered in the deep-sea hydrothermal vents, Alteromonas infernus, was shown to excrete a water-soluble branched acidic heteropolysaccharide 


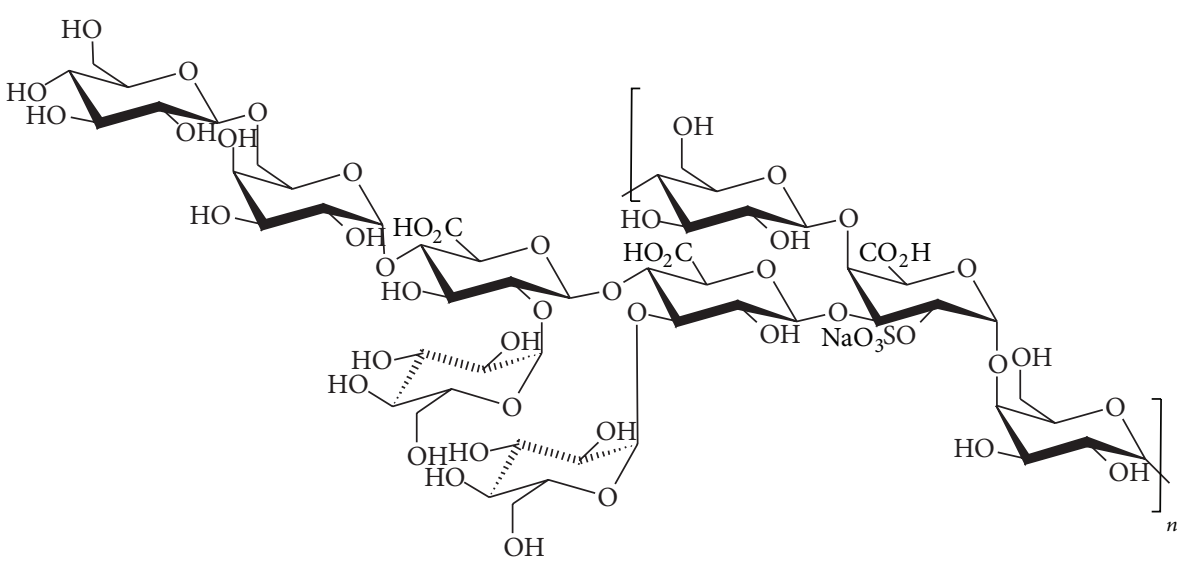

FIGURE 1: Structure of the monosulfated nonasaccharide repeating unit of the native bacterial GY785 EPS.

named GY785 (Figure 1) with a high molecular weight (HMW, i.e., $>10^{6} \mathrm{~g} / \mathrm{mol}$ ) and low sulfur content (up to $3 \mathrm{wt} \%$ ) [6]. This marine prokaryote was classified as a nonpathogenic microorganism by the Institute Pasteur (Paris, France). Moreover, the recent development of powerful bacterial engineering tools, such as large-scale fermenters, allows the production of the EPS at a viable economic cost by biotechnological processes [7].

The repeating unit of GY785 EPS consists of a monosulfated nonasaccharide composed of three uronic acids (two glucuronic acids and one galacturonic acid) and six neutral hexoses (four glucoses and two galactoses) [8]. The galacturonic acid unit is the only one sugar bearing a sulfate group at C2 position giving a slightly sulfated EPS (Figure 1). Structural modifications were shown to be essential for promoting the biological activity of this EPS and providing a GAG mimetic compound [9-12]. Firstly, a depolymerization step of the native HMW polysaccharide afforded a low-molecular weight (LMW) derivative, GY785 $\mathrm{DR}$, and then a subsequent chemical sulfation reaction gave a highly sulfated LMW derivative, GY785 DRS, with a sulfur content up to $12 \mathrm{wt} \%$ [9]. Recently, the effect of this derivative on chondrogenesis was investigated and has shown that being added to a chondrogenic differentiation medium, containing chondrogenic growth factors such as TGF- $\beta 1$, GY785 DRS enhanced the chondrogenic differentiation of mesenchymal stem cells, considered as an attractive source of cells for cartilage engineering [13].

The efficient production of semisynthetic GAG mimetic derivatives through chemical sulfation still remains a challenge since it presents several limitations: (i) bringing together hydrophilic natural macromolecules and organic reagents in homogeneous conditions, (ii) difficulties for driving the reaction to completion due to anionic interactions which increase with the number of linked sulfate groups, (iii) lack of control and reproducibility towards the reaction (e.g., regioselectivity), (iv) lability of sulfate groups in acidic conditions or at high temperatures, and (v) difficulty to remove high proportion of inorganic salts at the end of the reaction [14]. Considering that highly sulfated products have valuable biological targets and that the sulfate groups are sensitive, sulfation reaction is mostly performed as final chemical modification of the polysaccharide structure.

Sulfated polysaccharide derivatives can be obtained by a chemical modification under non homogeneous or homogeneous conditions. Homogeneous media are more attractive since they induce equal accessibility of polysaccharidic hydroxyl groups to the sulfating agent thus increasing the efficiency of sulfation. A wide range of studies describes classical solvent-systems, such as $N, N^{\prime}$-dimethylacetamide (DMAc), lithium chloride ( $\mathrm{LiCl}$ ), dimethyl sulfoxide (DMSO), dimethylformamide (DMF), or tetrabutylammonium fluoride trihydrate (TBAF) to dissolve polysaccharides prior to their modification [15-18]. However, poor solubility of hydrophilic polysaccharides in organic solvents as well as important polysaccharide degradation during reaction limits their use as good solvents. Recently, ionic liquids (ILs) were shown to constitute innovative media for solubilization of polysaccharides thus promoting their efficient chemical modification [19]. Indeed, because ILs ease the dissolution of both organic and inorganic reagents, they are considered as excellent interfaces to promote carbohydrate chemistry [18-20]. The efficiency in disruption of the inter- and intramolecular hydrogen bonds in carbohydrates can be enhanced by using the hydrophilic IL, namely, 1-butyl-3-methylimidazolium chloride (BMImCl) [21-23]. Sulfation process in ILs has been mainly described for cellulose [24-27]. However, harsh reaction conditions used have caused an important backbone degradation [28-31].

In the present study, the IL mainly described as a new class of cellulose solvents was chosen for the first time to modify an anionic branched heteropolysaccharide, GY785 EPS. In order to develop a one-step and efficient sulfation process completely free of side effects (e.g., polysaccharide depolymerization and/or degradation) to produce GAG-like derivatives, the sulfation of GY785 DR in BMImCl medium was assessed. Moreover, in order to facilitate the transfer of the one-step process developed here into a large scale, only commercially available reagents were used. 


\section{Materials and Methods}

2.1. Materials. Sulfur trioxide pyridine complex $\left(\mathrm{SO}_{3} \cdot \mathrm{Py}\right.$, technical grade, $48.8-50.3 \%$ active $\mathrm{SO}_{3}$ ), $N, N^{\prime}$-dimethylformamide (DMF, 99.8\%, Extra Dry over Molecular Sieve, AcroSeal), and 4-dimethylaminopyridine (DMAP, 99\%) were purchased from Acros Organics. 1-Butyl-3-methylimidazolium chloride (BMImCl, 98\%, melting point, $72^{\circ} \mathrm{C}$ ) was obtained from Solvionic. Spectra/Por 6 Prewetted Dialysis Tubing (MWCO 1,000 Da, $1.1 \mathrm{~mL} / \mathrm{cm}$ ) was obtained from Interchim. All the reagents were purchased with an analytical grade. All ultrafiltration was performed with Pellicon 2 system and a membrane cut-off at 1,000 Da (surface $0.1 \mathrm{~m}^{2}$ Cassette Hystream Novasep, Millipore).

\subsection{Preparation and Purification of EPS and Its Derivatives}

2.2.1. Production of the Native GY785 EPS. GY785 EPS is produced by Alteromonas infernus, a deep-sea, aerobic, mesophilic, and heterotrophic bacterium isolated from a sample of fluid collected among a dense population of Riftia pachyptila in the vicinity of an active hydrothermal vent of the Southern depression of the Guaymas Basin (Gulf of California). The production and isolation of the EPS were previously described [32]. In the present study, GY785 EPS production was carried out at $25^{\circ} \mathrm{C}$ and $\mathrm{pH} 7.4$ in a $30 \mathrm{~L}$ fermenter (Techfors 30 L INFORS, Switzerland). Briefly, $20 \mathrm{~L}$ of Zobell medium, a marine culture medium prepared with $5 \mathrm{~g} / \mathrm{L}$ of bactopeptones, $1 \mathrm{~g} / \mathrm{L}$ of yeast extract, and $35 \mathrm{~g} / \mathrm{L}$ of sea salts, were introduced in the fermenter before addition of $2 \mathrm{~L}$ of cells suspension inoculum. The carbohydrate source necessary for biosynthesis of the EPS was $30 \mathrm{~g} / \mathrm{L}$ of glucose added at the beginning of the batch. At the end of the fermentation process, the EPS was recovered from the growth medium by a centrifugation step followed by ultrafiltration and freeze-drying.

2.2.2. Preparation of GY785 DR. GY785 DR was obtained by a free-radical depolymerization process. Briefly, $2.5 \mathrm{~g}$ of the native EPS was dissolved overnight in $350 \mathrm{~mL}$ of water in a water-jacketed glass vessel, without stirring. When a complete dissolution was achieved, an aqueous solution of the catalyst (copper(II)) was added under $\mathrm{pH}$ control and stirring. The resulting mixture was maintained at $60^{\circ} \mathrm{C}$ during the reaction and the $\mathrm{pH}$ was set at 7.5. A continuous addition of a diluted hydrogen peroxide solution $(1 \mathrm{~mL} / \mathrm{min})$ was then started under controlled $\mathrm{pH}$ conditions using a pHstat (Hach and Lange). The reaction was stopped when the amount of peroxide solution to be added was reached. The polysaccharide chains were stabilized by an overnight room temperature reduction reaction with sodium borohydride. Excess of sodium borohydride was then quenched with an aqueous solution of acetic acid $(10 \mathrm{M})$. The contaminating copper cations were chelated passing the previous aqueous solution through Chelex 20 resin (sodium form). The resulting solution was ultrafiltrated before being freeze-dried.

2.2.3. Preparation of Highly Sulfated GY785 DRS. The sulfation of the GY785 DR was performed either in $\mathrm{BMImCl}$ or in
DMF. Firstly, GY785 DR was sulfated in IL medium. Briefly, to a solution of premelted BMImCl $(950 \mathrm{mg})$ at $90^{\circ} \mathrm{C}, \mathrm{GY} 785$ DR $(50 \mathrm{mg}$ ) was added in one portion in a Schlenk tube. For a complete dissolution, the resulting mixture was stirred for $4 \mathrm{~h}$ at $90^{\circ} \mathrm{C}$ under reduced pressure (100 mbar). DMAP (5 mg) was then added to the mixture, followed by a suspension of $\mathrm{SO}_{3} \cdot \mathrm{Py}(250 \mathrm{mg})$ in $\mathrm{DMF}(0.5 \mathrm{~mL})$. The reaction mixture was stirred for $2 \mathrm{~h}$ at $70^{\circ} \mathrm{C}$ under atmospheric pressure. After dilution with water $(10 \mathrm{~mL})$ and cooling to room temperature, the solution $\mathrm{pH}$ was adjusted to $7-8$ with $\mathrm{NaOH}(3 \mathrm{~N})$. The final solution was dialyzed against distilled water for $72 \mathrm{~h}$ to remove BMImCl, DMAP, DMF, excess of $\mathrm{SO}_{3} \cdot \mathrm{Py}$, and potential degradation products before being freeze-dried.

The kinetic of sulfation was studied at $70^{\circ} \mathrm{C}$ by varying the time of sulfation: $0.5 \mathrm{~h}, 1 \mathrm{~h}, 2 \mathrm{~h}$, and $4.5 \mathrm{~h}$. The effect of temperature reaction was studied at four different temperatures: $65^{\circ} \mathrm{C}, 70^{\circ} \mathrm{C}, 90^{\circ} \mathrm{C}$, and $120^{\circ} \mathrm{C}$. Finally, the effect of sulfating agent was assessed by replacing the $\mathrm{SO}_{3} \cdot \mathrm{Py}$ by the sulfur trioxide trimethylamine complex $\left(\mathrm{SO}_{3} \cdot \mathrm{Me}_{3} \mathrm{~N}\right)$ and sulfur trioxide $N, N^{\prime}$-dimethylformamide complex $\left(\mathrm{SO}_{3} \cdot \mathrm{DMF}\right)$.

As previously described, the sulfation of the GY785 DR in anhydrous DMF was preceded by a preparation of GY785 DR in a pyridinium salt form by cation exchange chromatography using Dowex HCR-S column (Dow Chemical) [10]. The eluent was immediately neutralized by addition of the pyridine (pH 7-8). GY785 DR (50 mg) recovered after freezedrying of the GY785 DR pyridinium salt was solubilized in anhydrous DMF $(100 \mathrm{~mL})$ for $2 \mathrm{~h}$ at $45^{\circ} \mathrm{C}$ under continuous stirring. After a complete solubilization, $\mathrm{SO}_{3} \cdot \mathrm{Py}(250 \mathrm{mg})$ was added to the mixture and sulfation was followed for $2 \mathrm{~h}$ at $45^{\circ} \mathrm{C}$ under stirring. After dilution with water $(20 \mathrm{~mL})$ and cooling to room temperature, the solution $\mathrm{pH}$ was adjusted to 7-8 with $\mathrm{NaOH}(3 \mathrm{~N})$. The final solution was extensively dialyzed against distilled water for $72 \mathrm{~h}$ and freeze-dried.

2.2.4. Purification of GY785 DRS. In order to obtain a homogeneous fraction of GY785 DRS with both molecular weight of $10,000 \mathrm{~g} / \mathrm{mol}$ and low polydispersity, a predominant population of polysaccharide chains was selected by a gel filtration chromatography using an AKTA FPLC system (GE Healthcare Life Sciences) and refractometric detection (Gilson). The column XK 26/100 was filled with $500 \mathrm{~mL}$ Superdex 30 preparative grade gel (GE Healthcare Life Sciences). $5 \mathrm{~mL}$ of the sample, containing 400 to $700 \mathrm{mg}$ of GY785 DRS, were injected by using a superloop and eluted with $0.1 \mathrm{M}$ ammonium acetate for GYDRS sulfated with IL process and with deionized water for GYDRS sulfated with DMF process. Fractions of $10 \mathrm{~mL}$ were collected and pooled. GYDRS IL pool was additionally dialyzed against distilled water before being freeze-dried.

\subsection{Characterization of GY785 Derivatives}

2.3.1. Molecular Weight and the Polydispersity Index Determination by HPSEC-MALS. The weight-average molecular weight $(\mathrm{Mw})$, number-average molecular weight $(\mathrm{Mn})$, and the polydispersity index (Ip = Mw/Mn) of the samples were determined by high-performance size exclusion chromatography (HPSEC) coupled with a multiangle light scattering 
detector (MALS, Dawn Heleos-II, Wyatt Technology) and a differential refractive index (RI) detector (Hitachi L2490). HPSEC system was composed of an HPLC system Prominence Shimadzu, a PL aquagel-OH mixed, $8 \mu \mathrm{m}$ (Varian) guard column $(U 7.5 \mathrm{~mm} \times L 50 \mathrm{~mm})$, and a PL aquagel-OH mixed (Varian) separation column $(U 7.5 \times 300 \mathrm{~mm}$, operating range $\left.10^{2}-10^{7} \mathrm{~g} / \mathrm{mol}\right)$. GY785 DR and GY785 DRS were dissolved in distilled water at a concentration of $2 \mathrm{mg} / \mathrm{mL}$ and filtered through $0.45 \mu \mathrm{m}$ cellulose acetate syringe filter before being injected. The elution was performed at $1 \mathrm{~mL} / \mathrm{min}$ rate with $0.1 \mathrm{M}$ ammonium acetate containing $0.03 \% \mathrm{NaN}_{3}$, filtered through $0.1 \mu \mathrm{m}$ membrane (Durapore Membrane, PVDF, Hydrophilic type VVLP, Millipore). Data were computed with Astra software 6.1 (Wyatt Technology).

2.3.2. Determination of the Linked Sulfate Groups by HPAEC. The linked ester sulfate group content in the GY785 samples was determined using high-performance anion-exchange chromatography (HPAEC) by calculating the difference between the total sulfur contents present in the hydrolyzed sample and in the nontreated sample (free sulfur). Briefly, an aqueous solution of an internal standard, $\mathrm{KNO}_{3}(10 \mathrm{~g} / \mathrm{L})$, was added to an aqueous solution of GY785 DRS $(2 \mathrm{mg} / \mathrm{mL})$. The mixture was hydrolyzed with $\mathrm{HCl}(1 \mathrm{M})$ at $133^{\circ} \mathrm{C}$ for $4 \mathrm{~h} 20$. After cooling to room temperature and the addition of water $(4.5 \mathrm{~mL}), 800 \mu \mathrm{L}$ of the sample was analyzed by HPAEC (in triplicate). Before injection, all samples were filtered through membrane filters with $0.45 \mu \mathrm{m}$ pore size. The sulfate peak was attributed with retention time reference to $\mathrm{Na}_{2} \mathrm{SO}_{4}$ standard, investigated over the concentration range $1-8 \mathrm{mM} / \mathrm{L}$. The peak area response was found to be linear over this range $\left(r^{2} \geq 0.997\right)$. HPAEC analyses were carried out with Dionex DX-500 ion chromatographic instrument controlled using Chromeleon software (version 6.80). The chromatographic system was composed of Dionex GP40 gradient pump, EG40 eluent generator with EGC II KOH eluent generator cartridge (EluGen II Hydroxide), ED 40 electrochemical detector with ASRS $3004 \mathrm{~mm}$ conductivity suppressor, AS40 autosampler, and column compartment Ultimate 3000. Sample separation was conducted with the use of Dionex IonPac AS11-HC $(250 \mathrm{~mm} \times 4 \mathrm{~mm})$ analytical anion exchange column with a guard column IonPac AG11-HC (50 mm $\times 4 \mathrm{~mm})$.

2.3.3. Elemental Analysis. The total sulfate content was also determined by the elemental analysis performed by the Central Microanalysis Department of the CNRS (Gif-surYvette, France).

2.3.4. ATR-FTIR and NMR Spectroscopy. Infrared spectra of GY785 DR and GY785 DRS were recorded with a FT-IR VERTEX 70 spectrometer (Bruker) in ATR mode in the range $4000-500 \mathrm{~cm}^{-1}$.

NMR ${ }^{1} \mathrm{H}$ and ${ }^{13} \mathrm{C}$ spectra were recorded using Bruker Avance 500 spectrometer (Bruker BioSpin, Wissembourg, France) equipped with a $5 \mathrm{~mm}{ }^{1} \mathrm{H} /{ }^{13} \mathrm{C} /{ }^{15} \mathrm{~N}$ TCI cryoprobe at $25^{\circ} \mathrm{C}$. GY785 DR and GY785 DRS were dissolved in $700 \mu \mathrm{L}$ of 99.96\% deuterium oxide. Chemical shifts were expressed in parts per million (ppm) relative to tetramethylsilane (TMS) used as a reference.

\section{Results and Discussion}

Alteromonas infernus produces a water-soluble highly branched EPS, GY785, of high molecular weight $\left(>10^{6} \mathrm{~g} / \mathrm{mol}\right)$ and low sulfur content (up to $3 \mathrm{wt} \%$ ) [6]. In order to improve the biological properties of the native EPS and to obtain a GAG-like compound, the radical depolymerization leading to a low molecular weight GY785 DR followed by its chemical sulfation was shown to be necessary. Indeed, only the GY785 DRS with a sulfur content up to $12 \%$ was shown to stimulate the chondrogenic differentiation of the mesenchymal stem cells most likely through interaction with the growth factor, TGF- $\beta 1$ [13]. To get further insight into the regenerative mechanism induced by GY785 DRS, LMW sulfated polysaccharides with well-defined structural features (i.e., a molecular weight and a sulfur content) are required. In this context, a new method of polysaccharide sulfation was developed using IL as a reaction medium. In fact, the use of IL as solvent allows the reaction to be carried out in a homogeneous medium in one-step process, whereas, in classical solvents, such as DMF, an additional ion-exchange step leading to the polysaccharide in a pyridinium salt form is necessary to improve its solubility prior to sulfation [33]. GY785 DR sulfation in IL medium should lead to the sulfur content close to $12 \mathrm{wt} \%$, which confers to the resulting GY785 DRS its biological activity, as previously assessed [13].

3.1. Sulfation of GY785 DR. The sulfation reaction of GY785 $\mathrm{DR}$ in $\mathrm{BMImCl}$ was performed in one-step process without converting the polysaccharide into a pyridinium salt form. In order to enhance the nucleophilicity of the hydroxyl groups on the carbohydrate backbone, the efficient sulfating agent, namely, sulfur trioxide pyridine complex $\left(\mathrm{SO}_{3} \cdot \mathrm{Py}\right)$ [34], was chosen. In addition, the catalyst, 4-dimethylaminopyridine (DMAP), was added to the reaction mixture to increase the reaction rate thus decreasing the undesired depolymerization of the polysaccharide [28]. A small quantity of DMF was also added during the sulfation reaction to reduce the viscosity of the reaction medium. In parallel, the sulfation of GY785 DR was carried out in classical solvent, DMF [10].

A significant increase in both molecular weight (11,000 g/ mol) and sulfur content (10.4 wt\%) was observed for GY785 DRS obtained after sulfation performed in $\mathrm{BMImCl}$, in comparison to GY785 DR before sulfation $(7,500 \mathrm{~g} / \mathrm{mol}$ and $3 \mathrm{wt} \% \mathrm{~S})$. Indeed, a 1.5-fold increase in molecular weight was measured after sulfation, whereas the sulfur content rose 3.3 times (Table 1). The sulfur content obtained after sulfation in $\mathrm{BMImCl}$ was close to $10 \mathrm{wt} \%$, as in $\mathrm{DMF}$, giving a GY785 DRS with the capability to stimulate the chondrogenic differentiation of the mesenchymal stem cells [13].

A slight difference between the sulfur content determined by the elemental analysis and by HPAEC was observed and was partly due to the fact that the elemental analysis assesses the total sulfur content. In contrast, HPAEC allows us to determine the sulfur content directly linked to the 
TABLE 1: Molecular weight, Mw (g/mol), the polydispersity index, Ip and sulfur content, S (wt\%) of GY785 DR and GY785 DRS (before and after sulfation, respectively).

\begin{tabular}{lcccccc}
\hline Derivative & Solvent & Temp. $\left({ }^{\circ} \mathrm{C}\right)$ & $\overline{\mathrm{Mw}}(\mathrm{g} / \mathrm{mol})$ & $\mathrm{Ip}$ & $\mathrm{S}^{*}(\mathrm{wt} \%)$ & 3.4 \\
\hline GY785 DR & - & - & 7,500 & 1.1 & $\mathrm{~S}^{* *}(\mathrm{wt} \%)$ \\
\hline \multirow{2}{*}{ GY785 DRS } & BMImCl & 70 & 11,000 & 1.1 & 9.7 & 3.0 \\
& DMF & 45 & 16,000 & 1.1 & 10.4 \\
\hline
\end{tabular}

${ }^{*}$ Determined by the elemental analysis.

** Determined by HPAEC method.

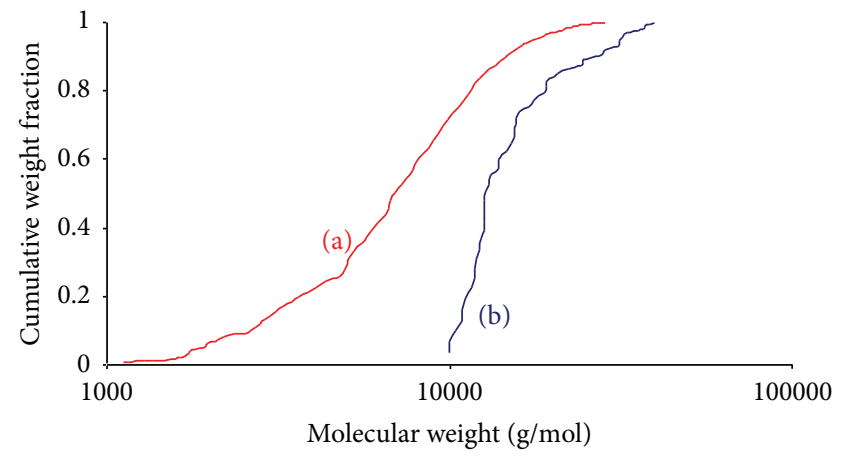

FIGURE 2: Cumulative molecular weight fraction of GY785 DRS with the dissolution step performed under atmospheric pressure (a) or under vacuum (100 mbar) (b).

polysaccharide by measuring the difference between the free sulfur present in the hydrolyzed and not hydrolyzed sample. In addition, a good sulfation reproducibility of GY785 DR with the sulfur content varying from $9 \mathrm{wt} \%$ to $11.6 \mathrm{wt} \%$ and a systematic increase in the molecular weight (data not shown) demonstrate that the sulfation reaction performed in $\mathrm{BMImCl}$ allows the efficient polysaccharide modification devoid of side effects (e.g., depolymerization or degradation).

It should be noted that the solubilization step preceding the sulfation reaction needs to be carried out under reduced pressure $(100 \mathrm{mbar})$, since an important chain degradation was observed during dissolution under atmospheric pressure (Figure 2). Indeed, at atmospheric pressure, a heterogeneous molecular weight distribution was obtained, with chain molecular weights ranging from 300 to $10,000 \mathrm{~g} / \mathrm{mol}$, whereas, a narrow molecular weight distribution was observed when the dissolution was performed under reduced pressure, most of the chains having a molecular weight close to $10,000 \mathrm{~g} / \mathrm{mol}$ (Figure 2). The observed degradation of the polysaccharide backbone under atmospheric pressure is most likely due to the presence of residual amount of water since GY785 DR and $\mathrm{BMImCl}$ are both hygroscopic compounds. Therefore, the water content must be reduced to permit firstly an easy dissolution of the polysaccharide in the IL and then to avoid the hydrolysis of the EPS by sulfuric acid formed when the sulfating agent $\mathrm{SO}_{3} \cdot \mathrm{Py}$ is added to the reaction medium [35]. To limit the moisture content and to prevent the polysaccharide degradation and/or depolymerization, the dissolution step was performed for $4 \mathrm{~h}$ at $90^{\circ} \mathrm{C}$, that is, a temperature higher than the melting point of the IL, and under reduced pressure (100 mbar).

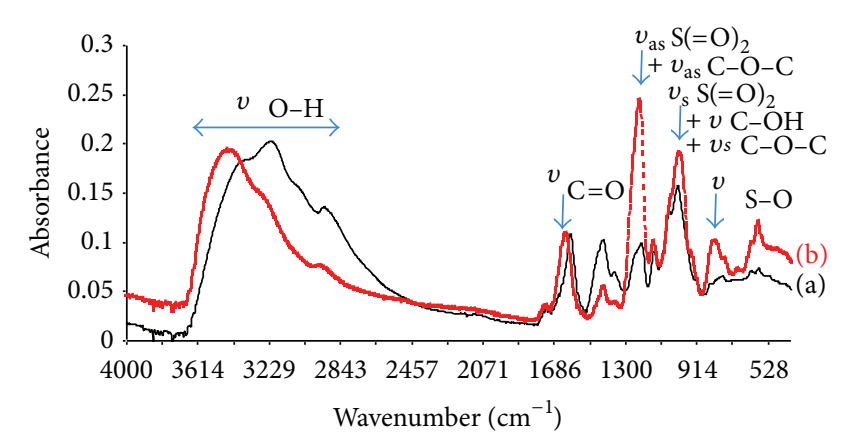

FIGURE 3: ATR FT-IR spectra of GY785 DR (a) and GY785 DRS sulfated in BMImCl medium (b).

The new sulfation process of GY785 DR developed in $\mathrm{BMImCl}$ as the reaction medium was compared to the classical sulfation method involving DMF as solvent [10]. The sulfation of GY785 DR in DMF led also to an increase in both molecular weight $(16,000 \mathrm{~g} / \mathrm{mol})$ and sulfur content (16 wt\%), when compared to GY785 DR (Table 1). Slightly higher sulfur content obtained after sulfation in DMF, when compared to sulfation proceeded in $\mathrm{BMImCl}(10 \mathrm{wt} \%)$, was most likely due to the fact that GY785 DR was firstly converted into its pyridinium salt before sulfation, which enhances its solubility and improves its modification [10]. However, higher sulfur content obtained in DMF compared to IL medium could not be necessarily beneficial. With a high degree of GAG sulfation, an increase in transient growth factor sequestration is observed and the intensity of growth factor activity (enhanced or inhibited) can be manipulated. Consequently, to regulate properly the sequestration (that is, the enhancement of growth factor activity but not its inhibition, which could occur with a too strong interaction between GAG and growth factor), a sulfur content close to $10 \mathrm{wt} \%$ is required for bioinspired GAG design [36].

3.2. Analyses of LMW-S Derivatives. ATR FT-IR spectra of initial GY785 DR and GY785 DRS obtained after sulfation in BMImCl medium are presented on Figure 3. Both spectra exhibited a broad $\mathrm{O}-\mathrm{H}$ stretching band at $3600-3000 \mathrm{~cm}^{-1}$, a minor $\mathrm{C}-\mathrm{H}$ stretching band at $2900 \mathrm{~cm}^{-1}$, a typical $\mathrm{C}=\mathrm{O}$ stretching band at $1650 \mathrm{~cm}^{-1}$, and a strong absorption band at $1050 \mathrm{~cm}^{-1}$ assigned to the $\mathrm{C}-\mathrm{O}$ and $\mathrm{C}-\mathrm{O}-\mathrm{H}$ vibrations. However, the differences between the two spectra were noticeable. The band associated with $\mathrm{O}-\mathrm{H}$ was considerably reduced 


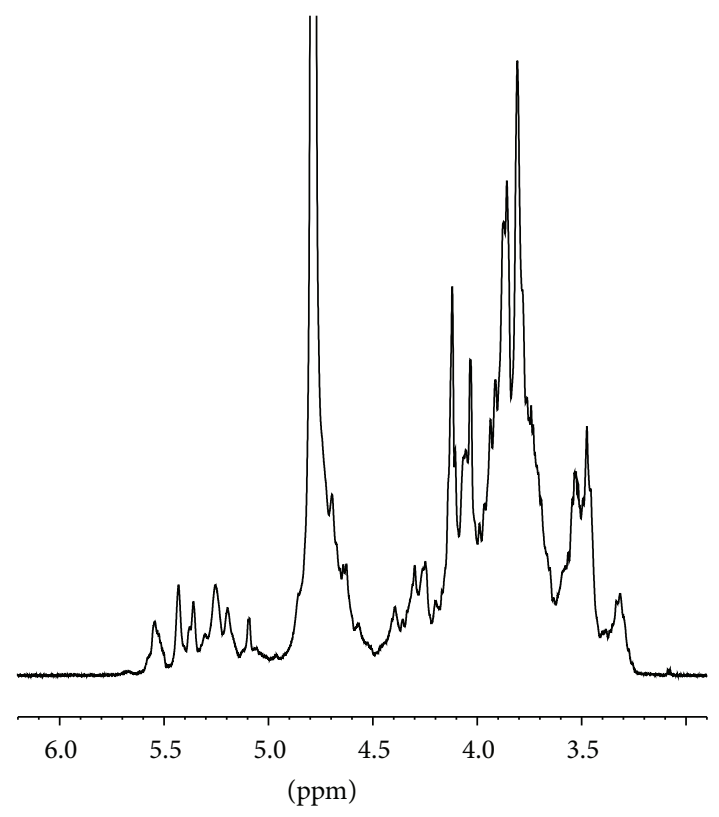

(a)

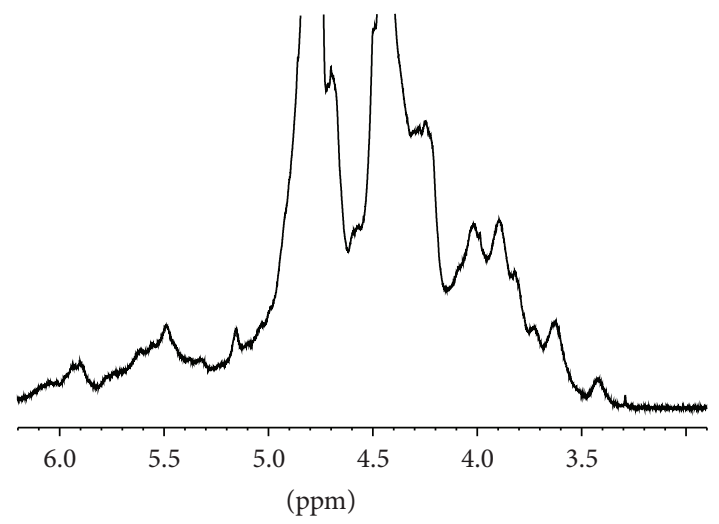

$\left(a^{\prime}\right)$
GY785 DR

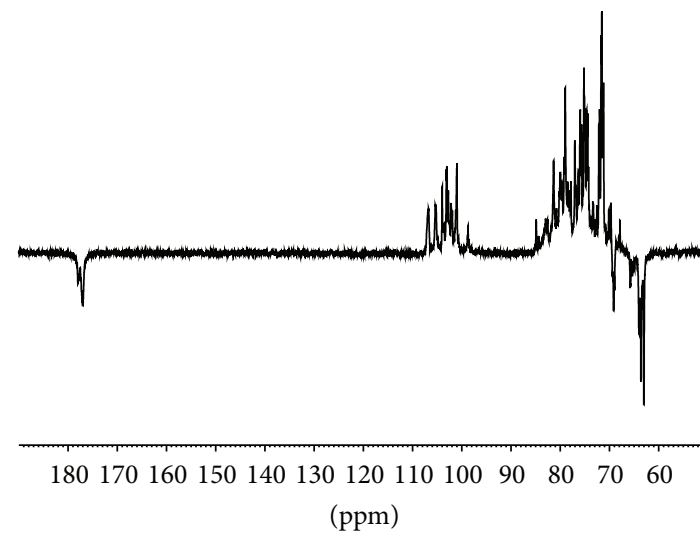

(b)

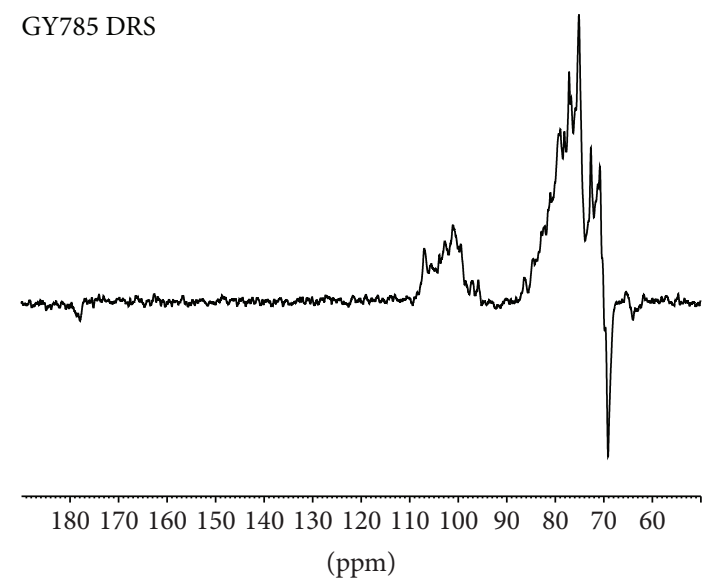

$\left(b^{\prime}\right)$

Figure 4: ${ }^{1} \mathrm{H}$ NMR spectra of GY785 DR (a) and GY785 DRS ( $\left.\mathrm{a}^{\prime}\right)$ and ${ }^{13} \mathrm{C}$ J-modulated NMR spectra of GY785 DR (b) and GY785 DRS (b').

in GY785 DRS due to the esterification of the hydroxyl groups during sulfation reaction. In addition, strong bands at $1250 \mathrm{~cm}^{-1}$ and $816 \mathrm{~cm}^{-1}$, observed in GY785 DRS spectrum, assigned, respectively, to $\mathrm{S}=\mathrm{O}$ asymmetric stretching and $\mathrm{S}-$ O symmetric vibrations, indicate clearly that the sulfation of hydroxyl groups actually occurred.

The efficiency of sulfation was also demonstrated by NMR spectroscopy. ${ }^{1} \mathrm{H}$ and ${ }^{13} \mathrm{C}$ NMR spectra of GY785 DR and GY785 DRS are presented on Figure 4. In ${ }^{1} \mathrm{H}$ NMR spectra, peaks corresponding to anomeric region became complex after sulfation reaction and a large peak at $4.4 \mathrm{ppm}$ and new signals at $6 \mathrm{ppm}$ appeared. More complex ${ }^{13} \mathrm{C}$ NMR spectrum of GY785 DRS and the $\mathrm{CH}_{2}$ downfield chemical shift observed at $70 \mathrm{ppm}$ indicated the substitution of $\mathrm{CH}_{2}-\mathrm{OH}$ groups after sulfation reaction. However, further extensive NMR analyses have to be carried out in order to determine precisely the sulfation pattern and the position of added sulfate groups on the GY785 DRS backbone [37].

In order to get further insight into the sulfation of GY785 $\mathrm{DR}$ in $\mathrm{BMImCl}$, the influence of time, temperature, and sulfation agent on both molecular weight and sulfur content was studied.

3.3. Effect of the Reaction Time on the Sulfation Reaction. Firstly, the kinetic of sulfation in BMImCl was studied. For this purpose, the sulfation was performed for four different reaction times: $0.5 \mathrm{~h}, 1 \mathrm{~h}, 2 \mathrm{~h}$, and $4.5 \mathrm{~h}$. Figure 5 presents, for each reaction time, the variation of the molecular weight before and after sulfation (blue bar giving the multiplier 
TABLE 2: Molecular weight, Mw (g/mol), the polydispersity index, Ip and sulfur content, S (wt\%) of GY785 DR and GY785 DRS obtained after sulfation carried out at different temperatures.

\begin{tabular}{|c|c|c|c|c|c|}
\hline Derivative & Temp. $\left({ }^{\circ} \mathrm{C}\right)$ & $\overline{\mathrm{Mw}}(\mathrm{g} / \mathrm{mol})$ & Ip & $S^{*}(w t \%)$ & $\mathrm{S}^{* *}(\mathrm{wt} \%)$ \\
\hline GY785 DR & - & 7,500 & 1.1 & 3.4 & 3.0 \\
\hline \multirow{4}{*}{ GY785 DRS } & 65 & 9,000 & 1.1 & 8.2 & 7.6 \\
\hline & 70 & 11,000 & 1.1 & 9.7 & 10.4 \\
\hline & 90 & 10,500 & 1.1 & 11.2 & 11.1 \\
\hline & 120 & 8,000 & 1.3 & 10.7 & 10.1 \\
\hline
\end{tabular}

* Determined by the elemental analysis.

${ }^{* *}$ Determined by HPAEC method.

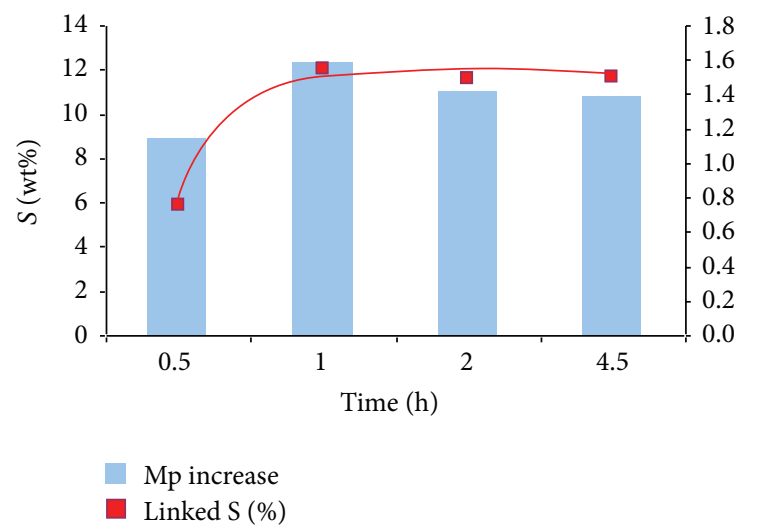

FIGURE 5: Comparison of the variation of the molecular weight and the sulfur content in GY785 DRS recovered following different sulfation time.

between the two molecular masses), while the red line represents the sulfur content (wt\%) in the final GY785 DRS. The rapid increase in the sulfur content in GY785 DRS suggests that the esterification of the hydroxyl groups was fast and occurred in the first minutes of the reaction to reach at $1 \mathrm{~h}$ a level of $12 \mathrm{wt} \%$ of the sulfur content. The efficiency of the esterification reaction could be explained by the presence of DMAP catalyst which promoted and accelerated the substitution step. DMF added during the sulfation reaction reduced the solution viscosity, which improved homogeneous sulfation conditions. When the reaction time was increased above $1 \mathrm{~h}$, no further increase in the sulfur content was observed (11 wt\%). However, a slight decrease in the variation of molecular weight was noticed with increasing reaction time, which was most likely due to the unwanted polymer backbone degradation initiated by hydrolysis by sulfuric acid formed from the sulfating agent [35].

3.4. Effect of Temperature on the Sulfation Reaction. In order to assess the effect of temperature on sulfation efficiency, the reaction was carried out at four different temperatures: $65^{\circ} \mathrm{C}$, $70^{\circ} \mathrm{C}, 90^{\circ} \mathrm{C}$, and $120^{\circ} \mathrm{C}$ (Table 2). Similar results were obtained when sulfation of GY785 DR was performed at the temperatures between $70^{\circ} \mathrm{C}$ and $120^{\circ} \mathrm{C}$. Indeed, the sulfur content in GY785 DRS varied only slightly between $10 \mathrm{wt} \%$ and $11 \mathrm{wt} \%$. At $120^{\circ} \mathrm{C}$, even if a satisfying sulfur amount of $10 \mathrm{wt} \%$ was obtained, a brown aspect of the freeze-dried final product and higher polydispersity index suggests the degradation of the polysaccharide structure. The sulfation performed at $65^{\circ} \mathrm{C}$ led to a lower sulfur content, as only $7.6 \mathrm{wt} \%$ was measured. It becomes therefore that a temperature between $70^{\circ} \mathrm{C}$ and $90^{\circ} \mathrm{C}$ is more suitable for the sulfation reaction of GY785 DR in $\mathrm{BMImCl}$.

3.5. Effects of Sulfation Agent on the Sulfation Reaction. In order to assess the influence of the nature of sulfating reagent, in addition to $\mathrm{SO}_{3} \cdot \mathrm{Py}$, two commercially available reagents were selected: sulfur trioxide trimethylamine complex $\left(\mathrm{SO}_{3} \cdot \mathrm{Me}_{3} \mathrm{~N}\right)$ and sulfur trioxide $N, N^{\prime}$ dimethylformamide complex $\left(\mathrm{SO}_{3} \cdot \mathrm{DMF}\right)$. The well-known sulfur trioxide complex associated with aromatic amine pyridine $\left(\mathrm{SO}_{3} \cdot \mathrm{Py}\right)$ used in the present study to develop a sulfation process in IL was used as a reference. The second sulfation reagent was $\mathrm{SO}_{3} \cdot \mathrm{Me}_{3} \mathrm{~N}$ complex, where trimethylamine is a stronger base than pyridine. The tertiary amine released from the complex during the reaction plays a role of acid scavenger [38] and should prevent the polysaccharide from acidic degradation. The third sulfation agent selected, $\mathrm{SO}_{3} \cdot \mathrm{DMF}$ complex, shows different assets. DMF is a weaker base than pyridine, which implies that the partial positive charge on the sulfur atom of the $\mathrm{SO}_{3}$.DMF complex would be greater than that in the $\mathrm{SO}_{3} \cdot$ Py complex. Thus, the nucleophilic attack on the $\mathrm{SO}_{3} \cdot \mathrm{DMF}$ complex would be promoted and could increase the sulfur amount in the final product. Moreover, during the sulfation reaction DMF could also be released from the sulfating complex, which may decrease the medium viscosity and enhance sulfation as well.

Similar sulfur content obtained after sulfation with different sulfating agents (varying from $10.4 \mathrm{wt} \%$ to $10.7 \mathrm{wt} \%$, Table 3) suggests that the efficiency of sulfation is similar whatever the sulfating agent used. This could be explained by important structural complexity of GY785 DR, which results in low accessibility of hydroxyl groups for sulfation reaction. In addition, $\mathrm{SO}_{3}$. DMF, more reactive sulfation complex than $\mathrm{SO}_{3} \cdot \mathrm{Py}$, could be more rapidly degraded by residual water present in the reaction medium, which may decrease its efficiency as a sulfating agent.

More differences were observed in the molecular weights after sulfation. Indeed, the sulfation procedure using $\mathrm{SO}_{3} \cdot \mathrm{Py}$ complex afforded a polymer chains with the highest molecular weight $(10,000 \mathrm{~g} / \mathrm{mol})$ and a narrow polydispersity. On the 
TABLE 3: Molecular weight, Mw (g/mol), the polydispersity index, Ip and sulfur content, $\mathrm{S}$ (wt\%) of GY785 DR and GY785 DRS obtained after sulfation with different sulfation agents.

\begin{tabular}{lccccc}
\hline Derivative & Sulfation agent & $\overline{\mathrm{Mw}}(\mathrm{g} / \mathrm{mol})$ & $\mathrm{Ip}$ & $\mathrm{S}^{*}(\mathrm{wt} \%)$ & 3.4 \\
\hline GY785 DR & - & 7,500 & 10,000 & 1.1 & $\mathrm{~S}^{* *}(\mathrm{wt} \%)$ \\
\hline \multirow{3}{*}{ GY785 DRS } & $\mathrm{SO}_{3} \cdot \mathrm{Py}$ & 9,000 & 1.1 & 9.7 & 3.0 \\
& $\mathrm{SO}_{3} \cdot \mathrm{DMF}$ & 9,000 & 1.3 & 11.7 & 10.4 \\
& $\mathrm{SO}_{3} \cdot \mathrm{Me}_{3} \mathrm{~N}$ & 1.2 & 7.5 & 10.5 \\
\hline
\end{tabular}

${ }^{*}$ Determined by the elemental analysis.

** Determined by HPAEC method.

contrary, for the same sulfur content, an increase in molecular weight of GY785 DRS sulfated with $\mathrm{SO}_{3} \cdot \mathrm{Me}_{3} \mathrm{~N}$ or $\mathrm{SO}_{3} \cdot \mathrm{DMF}$ was lower $(9,000 \mathrm{~g} / \mathrm{mol})$ when compared to GY785 DRS sulfated with $\mathrm{SO}_{3}$.Py. In addition, the polydispersity index slightly increased after sulfation (Table 3 ). Lower molecular weights and higher polydispersity indexes of GY785 DRS sulfated with $\mathrm{SO}_{3} \cdot \mathrm{Me}_{3} \mathrm{~N}$ or $\mathrm{SO}_{3} \cdot \mathrm{DMF}$ suggest that the polysaccharide structure was slightly degraded during the reaction. Therefore, $\mathrm{SO}_{3} \cdot \mathrm{Py}$ remains as the best sulfating agent for GY785 DR modification.

\section{Conclusions}

In the present work, a one-step chemical sulfation process was successfully developed using $\mathrm{BMImCl}$ as a reaction medium without undesired degradation of the polysaccharide backbone. The homogeneous dissolution of the polysaccharides in IL was the main challenge of this process. The sulfation reaction was shown to be optimal at $70^{\circ} \mathrm{C}$ using $\mathrm{SO}_{3} \cdot \mathrm{Py} / \mathrm{DMAP} / \mathrm{DMF}$ as the sulfation system. The final GY785 DRS was obtained with a good yield and the reproducibility of sulfation by a rigorous control of both sulfur content and molecular weight was assessed. Moreover, it was demonstrated that the sulfur content can be modulated by varying the temperature or the time of the reaction. In conclusion, the new sulfation process developed in the present study using IL as reaction medium appears as a promising method leading to new GAG mimetic derivatives from marine origin. Further studies of GY785 DRS fine structure (i.e., the position of the sulfate groups on the polysaccharide backbone) would help to understand the influence of the structure on the biological properties of GY785 DRS.

The production of tailor-made oligosaccharide or polysaccharide structures by biotechnological process is a growing field of interest. This kind of process would facilitate the production of new macromolecules with high specificity for biological targets such as tissue engineering or regenerative medicine.

\section{Conflict of Interests}

The authors declare that there is no conflict of interests regarding the publication of this paper.

\section{Acknowledgments}

Financial supports were provided by the BIOREGOS II network and IONIBIOGEL ANR Blanc SIMI 9 (ANR, Agence Nationale de la Recherche, France). The authors would like to thank Professor B. Humbert (Université de Nantes, France) for ATR FT-IR spectra.

\section{References}

[1] A. C. Rapraeger, "Syndecan-regulated receptor signaling," The Journal of Cell Biology, vol. 149, no. 5, pp. 995-998, 2000.

[2] D. L. Rabenstein, "Heparin and heparan sulfate: structure and function," Natural Product Reports, vol. 19, no. 3, pp. 312-331, 2002.

[3] R. J. Linhardt and S. Claude, "Hudson award address in carbohydrate chemistry. Heparin: structure and activity," Journal of Medicinal Chemistry, vol. 46, no. 13, pp. 2551-2564, 2003.

[4] P. M. Kharkar, K. L. Kiick, and A. M. Kloxin, "Designing degradable hydrogels for orthogonal control of cell microenvironments," Chemical Society Reviews, vol. 42, no. 17, pp. 73357372, 2013.

[5] M. D. Freedman, "Pharmacodynamics, clinical indications, and adverse effects of heparin," The Journal of Clinical Pharmacology, vol. 32, no. 7, pp. 584-596, 1992.

[6] G. H. C. Raguénès, A. Peres, R. Ruimy et al., "Alteromonas infernus sp. Nov., a new polysaccharideproducing bacterium isolated from a deep-sea hydrothermal vent," Journal of Applied Microbiology, vol. 82, no. 4, pp. 422-430, 1997.

[7] D. Cimini, M. de Rosa, and C. Schiraldi, "Production of glucuronic acid-based polysaccharides by microbial fermentation for biomedical applications," Biotechnology Journal, vol. 7, no. 2, pp. 237-250, 2012.

[8] O. Roger, N. Kervarec, J. Ratiskol, S. Colliec-Jouault, and L. Chevolot, "Structural studies of the main exopolysaccharide produced by the deep-sea bacterium Alteromonas infernus," Carbohydrate Research, vol. 339, no. 14, pp. 2371-2380, 2004.

[9] S. Colliec Jouault, L. Chevolot, D. Helley et al., "Characterization, chemical modifications and in vitro anticoagulant properties of an exopolysaccharide produced by Alteromonas infernus," Biochimica et Biophysica Acta: General Subjects, vol. 1528, no. 2-3, pp. 141-151, 2001.

[10] K. Senni, F. Gueniche, M. Yousfi et al., "Sulfated depolymerized derivatives of exopolysaccharides (EPS) from mesophilic marine bacteria, method for preparing same, and use thereof in tissue regeneration," US 2008/0131472. 
[11] K. Senni, J. Pereira, F. Gueniche et al., "Marine polysaccharides: a source of bioactive molecules for cell therapy and tissue engineering," Marine Drugs, vol. 9, no. 9, pp. 1664-1681, 2011.

[12] P. Laurienzo, "Marine polysaccharides in pharmaceutical applications: an overview," Marine Drugs, vol. 8, no. 9, pp. 2435-2465, 2010.

[13] C. Merceron, S. Portron, C. Vignes-Colombeix et al., "Pharmacological modulation of human mesenchymal stem cell chondrogenesis by a chemically oversulfated polysaccharide of marine origin: potential application to cartilage regenerative medicine," Stem Cells, vol. 30, no. 3, pp. 471-480, 2012.

[14] R. A. Al-Horani and U. R. Desai, "Chemical sulfation of small molecules-advances and challenges," Tetrahedron, vol. 66, no. 16, pp. 2907-2918, 2010.

[15] H. Ronghua, D. Yumin, and Y. Jianhong, "Preparation and anticoagulant activity of carboxybutyrylated hydroxyethyl chitosan sulfates," Carbohydrate Polymers, vol. 51, no. 4, pp. 431-438, 2003.

[16] S. Bo, T. Muschin, T. Kanamoto, H. Nakashima, and T. Yoshida, "Sulfation and biological activities of konjac glucomannan," Carbohydrate Polymers, vol. 94, no. 2, pp. 899-903, 2013.

[17] H. Wang, G. Gurau, and R. D. Rogers, "Ionic liquid processing of cellulose," Chemical Society Reviews, vol. 41, no. 4, pp. 15191537, 2012.

[18] A. Pinkert, K. N. Marsh, S. Pang, and M. P. Staiger, "Ionic liquids and their interaction with cellulose," Chemical Reviews, vol. 109, no. 12, pp. 6712-6728, 2009.

[19] M. E. Zakrzewska, E. Bogel-Yukasik, and R. Bogel-Yukasik, "Solubility of carbohydrates in ionic liquids," Energy \& Fuels, vol. 24, no. 2, pp. 737-745, 2010.

[20] V. Prasad, R. R. Kale, V. Kumar, and V. K. Tiwari, "Carbohydrate chemistry and room temperature ionic liquids (RTILs): recent trends, opportunities, challenges and future perspectives," Current Organic Synthesis, vol. 7, no. 5, pp. 506-531, 2010.

[21] R. C. Remsing, R. P. Swatloski, R. D. Rogers, and G. Moyna, "Mechanism of cellulose dissolution in the ionic liquid 1-nbutyl-3- methylimidazolium chloride: a ${ }^{13} \mathrm{C}$ and ${ }^{35 / 37} \mathrm{Cl} \mathrm{NMR}$ relaxation study on model systems," Chemical Communications, no. 12, pp. 1271-1273, 2006.

[22] J. S. Moulthrop, R. P. Swatloski, G. Moyna, and R. D. Rogers, "High-resolution 13C NMR studies of cellulose and cellulose oligomers in ionic liquid solutions," Chemical Communications, no. 12, pp. 1557-1559, 2005.

[23] R. P. Swatloski, S. K. Spear, J. D. Holbrey, and R. D. Rogers, "Dissolution of cellose with ionic liquids," Journal of the American Chemical Society, vol. 124, no. 18, pp. 4974-4975, 2002.

[24] M. Gericke, A. Doliška, J. Stana, T. Liebert, T. Heinze, and K. Stana-Kleinschek, "Semi-synthetic polysaccharide sulfates as anticoagulant coatings for PET, 1-cellulose culfate," Macromolecular Bioscience, vol. 11, no. 4, pp. 549-556, 2011.

[25] M. Gericke, T. Liebert, O. A. E. Seoud, and T. Heinze, “Tailored media for homogeneous cellulose chemistry: ionic liquid/cosolvent mixtures," Macromolecular Materials and Engineering, vol. 296, no. 6, pp. 483-493, 2011.

[26] M. Gericke, T. Liebert, and T. Heinze, "Interaction of ionic liquids with polysaccharides, 8-synthesis of cellulose sulfates suitable for polyelectrolyte complex formation," Macromolecular Bioscience, vol. 9, no. 4, pp. 343-353, 2009.

[27] O. A. El Seoud, A. Koschella, L. C. Fidale, S. Dorn, and T. Heinze, "Applications of ionic liquids in carbohydrate chemistry: a window of opportunities," Biomacromolecules, vol. 8, no. 9, pp. 2629-2647, 2007.
[28] T. Chen, B. Li, Y. Li, C. Zhao, J. Shen, and H. Zhang, "Catalytic synthesis and antitumor activities of sulfated polysaccharide from Gynostemma pentaphyllum Makino," Carbohydrate Polymers, vol. 83, no. 2, pp. 554-560, 2011.

[29] Z. M. Wang, K. J. Xiao, L. Li, and J. Y. Wu, "Molecular weight-dependent anticoagulation activity of sulfated cellulose derivatives," Cellulose, vol. 17, no. 5, pp. 953-961, 2010.

[30] Z.-M. Wang, L. Li, K.-J. Xiao, and J.-Y. Wu, "Homogeneous sulfation of bagasse cellulose in an ionic liquid and anticoagulation activity," Bioresource Technology, vol. 100, no. 4, pp. 1687-1690, 2009.

[31] Z. M. Wang, L. Li, B. S. Zheng, N. Normakhamatov, and S. Y. Guo, "Preparation and anticoagulation activity of sodium cellulose sulfate," International Journal of Biological Macromolecules, vol. 41, no. 4, pp. 376-382, 2007.

[32] J. Guezennec, P. Pignet, Y. Lijour, E. Gentric, J. Ratiskol, and S. Colliec-Jouault, "Sulfation and depolymerization of a bacterial exopolysaccharide of hydrothermal origin," Carbohydrate Polymers, vol. 37, no. 1, pp. 19-24, 1998.

[33] J. Kovensky and A. F. Cirelli, "Chemical modification of glycosaminoglycans. Selective 2-sulfation of D-glucuronic acid units in heparan sulfate," Carbohydrate Research, vol. 303, no. 1, pp. 119-122, 1997.

[34] E. E. Gilbert, "The reactions of sulfur trioxide, and its adducts, with organic compounds," Chemical Reviews, vol. 62, no. 6, pp. 549-588, 1962.

[35] T. Liebert and T. Heinze, "Interaction of ionic liquids wlth polysaccharides 5 . Solvents and reaction media for the modification of cellulose," BioResources, vol. 3, no. 2, pp. 576-601, 2008.

[36] R. A. Hortensius and B. A. C. Harley, "The use of bioinspired alterations in the glycosaminoglycan content of collagen-GAG scaffolds to regulate cell activity," Biomaterials, vol. 34, no. 31, pp. 7645-7652, 2013.

[37] Y. Wang, X. Shen, W. Liao et al., "A heteropolysaccharide, 1-fucod-manno-1,6- $\alpha$-d-galactan extracted from Grifola frondosa and antiangiogenic activity of its sulfated derivative," Carbohydrate Polymers, vol. 101, no. 1, pp. 631-641, 2014.

[38] D. Papy-Garcia, V. Barbier-Chassefière, V. Rouet et al., "Nondegradative sulfation of polysaccharides. Synthesis and structure characterization of biologically active heparan sulfate mimetics," Macromolecules, vol. 38, no. 11, pp. 4647-4654, 2005. 

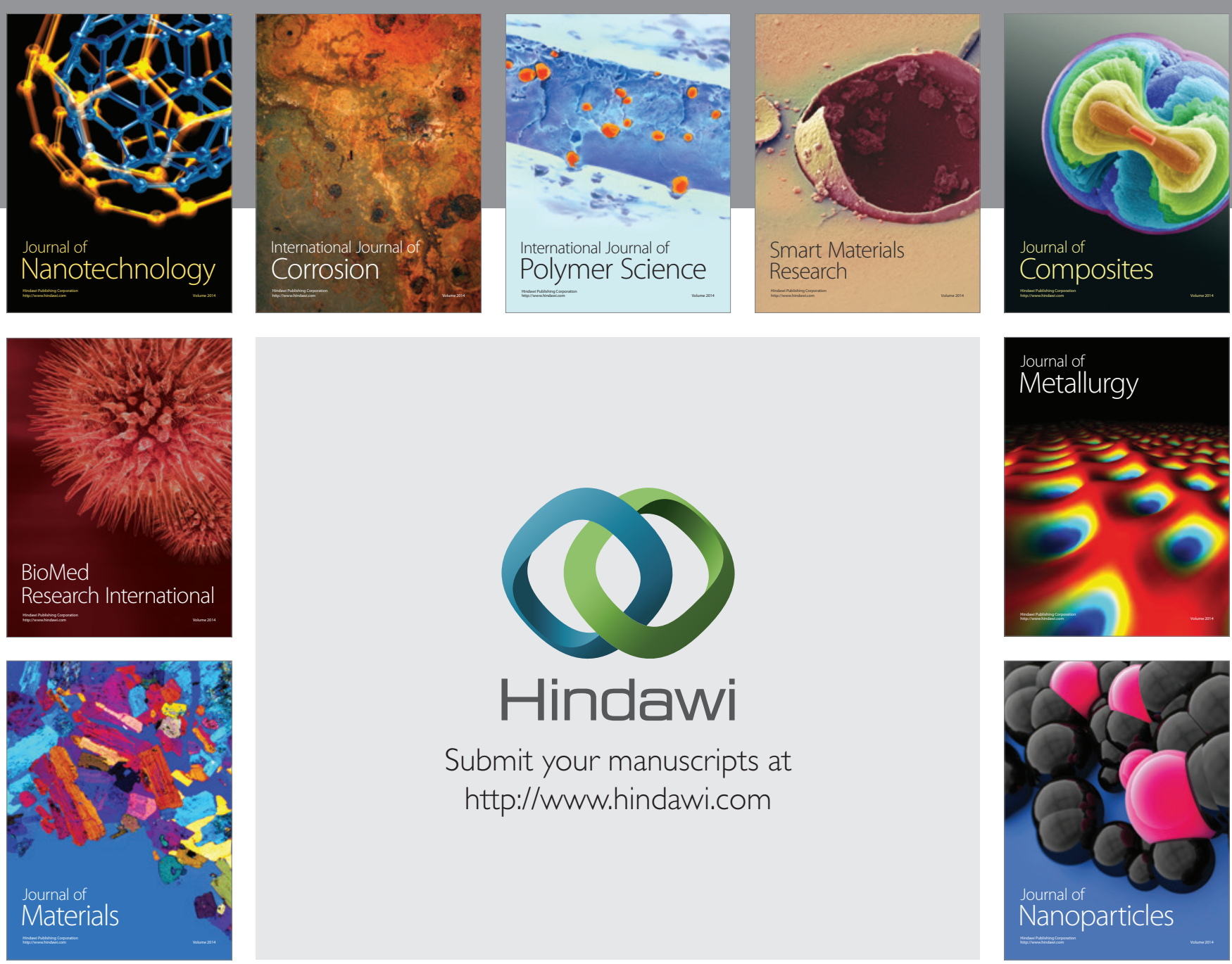

Submit your manuscripts at http://www.hindawi.com
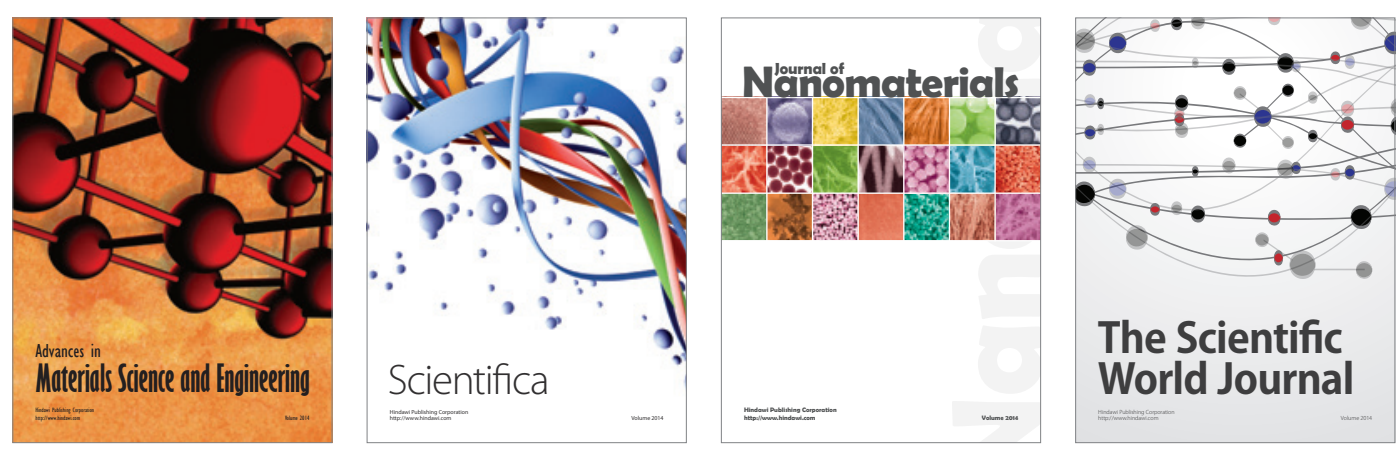

\section{The Scientific World Journal}
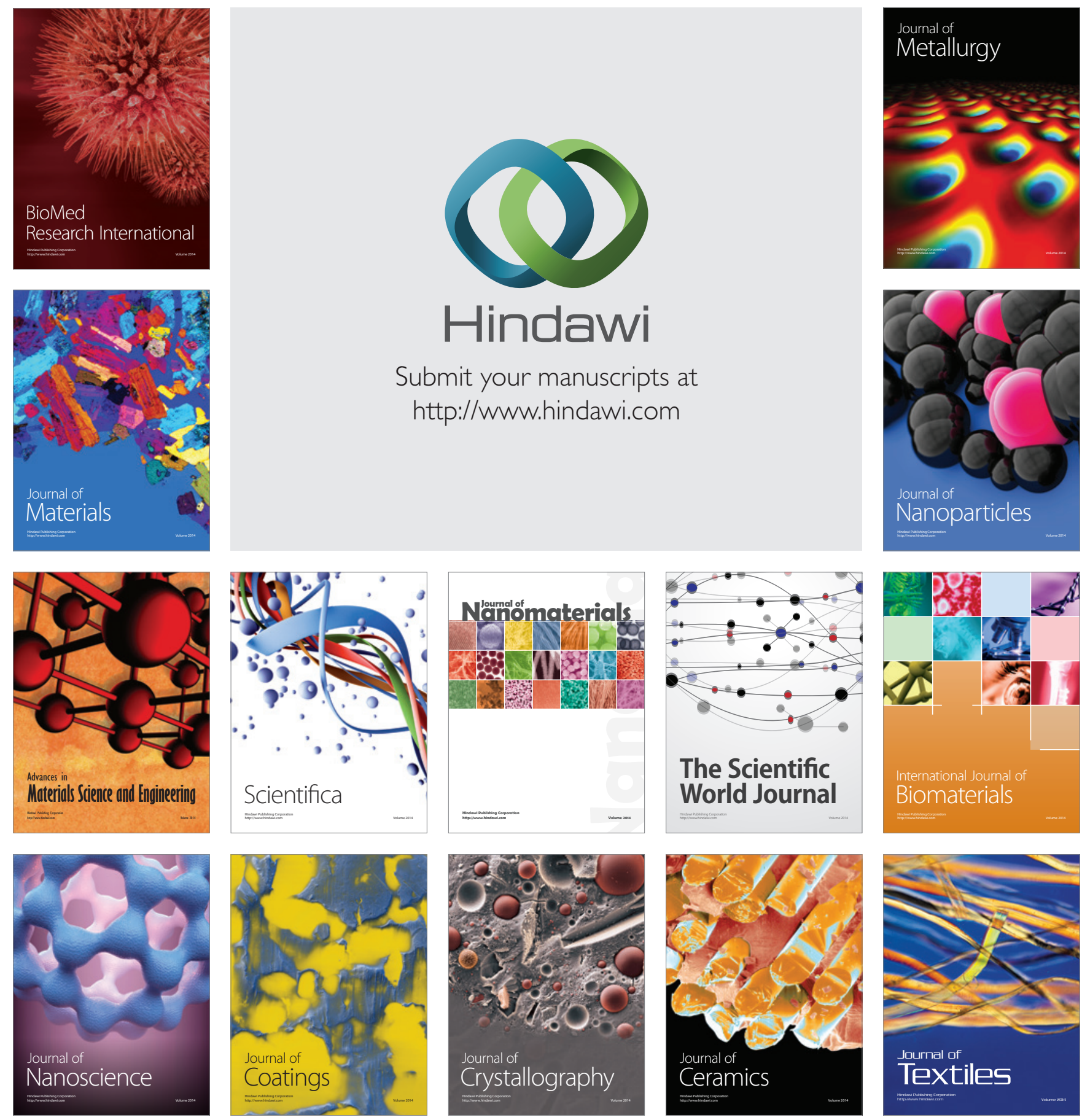